\title{
Research on the Status and Problems of Beijing "Textile Intangible Heritage +" Experiential Tourism
}

\author{
Miao Zhang ${ }^{1}$ Yongliang Wang ${ }^{2}{\text { Lei } \text { Yao }^{3} \text { ** }}^{*}$
}

\author{
${ }^{1}$ Beijing Institute of Fashion Technology, Beijing, 100029, China \\ ${ }^{2}$ Beijing Institute of Fashion Technology, Beijing, 100029, China \\ ${ }^{3}$ Beijing Institute of Fashion Technology, Beijing, 100029, China \\ *Corresponding author. Email: sxyyl@bift.edu.cn
}

\begin{abstract}
This article takes the Beijing area as the research area and proposes exploring the upgrade of Beijing experience tourism from the perspective of textile intangible cultural heritage. Beijing is the capital of China and has a profound cultural heritage. It is the gathering place of textile intangible cultural heritage across the country. Taking Beijing as a research area has reference significance and benchmarking role in the development of "textile intangible cultural heritage $+"$ experience tourism in other places. This article is combined of literature method and survey questionnaire research method, and conducts statistical analysis by consulting related literature and designing survey questionnaires. Analyze consumers' attitudes towards "textile intangible cultural heritage +" experiential tourism, analyzing existing problems, and then propose policy recommendations to promote the upgrade of Beijing experiential tourism and the inheritance of textile intangible cultural heritage.
\end{abstract}

Keywords: Questionnaire, Textile intangible cultural heritage, Experience tourism.

\section{INTRODUCTION}

Experiential tourism is different from traditional tourism. It has the characteristics of individualization, emotion and participation. However, the development of experiential tourism in actual life has limitations. Taking Beijing as the research area, exploring the upgrading of Beijing's experience tourism from the perspective of textile and intangible cultural heritage, and also responding to Beijing's "14th Five-Year Plan" cultural industry outlook: building Beijing into an innovative and creative city with international competitiveness.

Through the design of questionnaire surveys, the problems of Beijing's "Textile Intangible Cultural Heritage +" experience tourism were discovered and corresponding policy recommendations were given to provide suggestions on the supply side for the government's goal of building a "high-precision" cultural industry system. On the one hand, it combines experience tourism with textile intangible cultural heritage to build a complete "textile intangible cultural heritage + " experience tourism industry service system. On the other hand, economic development also enables textile intangible cultural heritage to be valued and inherited.

The research literature on "Textile Intangible Heritage + " experiential tourism in Beijing is still very scarce, but there are still some results in the research on "Textile Intangible Heritage" and "Experience Tourism" respectively.

Related research on textile intangible cultural heritage is mainly embodied in the scope, characteristics, classification, research methods and research theories of textile intangible cultural heritage. There are four specific research directions: the digital protection of textile intangible cultural heritage (Zhou Yiling, 2020), the promotion of textile intangible cultural heritage development by universities (Luo Xiaoqing, Tan Qingbao, 2020), the training of textile non-genetic inheritors, and the marketization of specific textile intangible cultural heritage classifications (Pan Weiwei, 2019).

Research on experiential tourism mainly focuses on the development of experiential tourism products and the integration with specific industries. Scholar Hou Baoli (2019) gives countermeasures and suggestions from the basic overview of specific industries, forms of 
integration, and market-oriented channels. Scholar Zhong Danni (2019) mainly improves product functions from the perspective of experience tourism to make it more marketable. In this process, the development and design of products are improved and more user-friendly and made specific suggestions.

In summary, the research on the status quo of Beijing "Textile Intangible Heritage +" experiential tourism is relatively scarce. How to integrate textile intangible heritage elements on the basis of experiential tourism will be the focus of this article.

\section{DEFINITION OF "TEXTILE INTANGIBLE CULTURAL HERITAGE +" EXPERIENCE TOURISM}

\subsection{Textile intangible cultural heritage concept}

According to the "China Textile Intangible Cultural Heritage Development Report (2017/2018)", the manifestations of textile intangible cultural heritage are divided into four aspects: (1) Embroidery techniques represented by Suzhou embroidery, Hunan embroidery, Shu embroidery, Guangdong embroidery, and ethnic embroidery. (2) Weaving techniques represented by silk, cotton, linen, and brocade weaving. (3) Printing and dyeing skills represented by blue calico, ethnic batik, tie-dyeing, etc. (4) Costume skills represented by ethnic minority costumes such as Inner Mongolia and Miao. The elements of textile intangible cultural heritage can be applied to the fashion industry, home furnishing industry, film and television industry and other fields.

\subsection{The concept of "textile intangible cultural heritage + " experience tourism}

Experiential tourism is an integral part of the experience economy. Experiential tourism activities provide consumers with participatory and personally experiential activities, so that tourists can feel fun during the journey. It is a special type of experience. Experiential tourism focuses on individualization, participation, and the whole process. Experiential tourism pays more attention to psychological perception and understanding in the process of participation, learning and perceiving culture in experience, and enriching the spiritual world.

"Textile intangible cultural heritage + " experiential tourism refers to a tourism method that combines elements of textile intangible cultural heritage in experiential tourism, such as adding a learning experience of textile intangible cultural heritage projects to experiential tourism. This paper uses the perspective of textile intangible cultural heritage to explore the upgrading of experience tourism consumption while spreading the culture of textile intangible cultural heritage. In this mode of tourism, travelers can learn and understand the culture of textile intangible cultural heritage in the process of experiencing tourism, so as to obtain a rich, profound and unforgettable travel experience. At the same time, travelers can also realize the essence of textile intangible cultural heritage and increase their awareness and understanding of textile intangible cultural heritage.

\section{QUESTIONNAIRE DESIGN AND BASIC SITUATION ANALYSIS}

\subsection{Questionnaire design}

Aiming at the purpose of this survey to explore the status quo and problems of Beijing's "Textile Intangible Heritage +" experience tourism, a questionnaire was designed to include the basic information of the survey object, intangible heritage, experience tourism, textile intangible heritage, and "Textile Intangible Heritage +" experience. There are a total of 18 questions in the five major aspects of tourism.

Use the Internet questionnaire star sample survey method to conduct the survey. The reason is that the exclusive questionnaire QR code can be formed through the questionnaire star, which saves time and economic costs compared to traditional offline questionnaires. The subjects of this questionnaire survey are residents in Beijing and travelers who have visited Beijing before. The suggestions of residents who have never been to Beijing are used as reference. A total of 284 people participated in this survey, of which 4 were invalidated due to unsound logic or missing answers, and 280 valid questionnaires.

\subsection{Analysis of the basic situation of the survey object}

\subsubsection{Age distribution}

The main subjects of this survey are mainly young people aged 19-30 and middle-aged people over 30 . Young people and middle-aged people have strong spending power. Those aged 19 to 30 accounted for $88.46 \%$, those aged over 30 accounted for $8.33 \%$, and minors accounted for $3.21 \%$. Experiential tourism is participatory and needs to be immersed in experience projects. Young consumer groups have a higher acceptance of new things and a greater degree of participation, and they are also the main experiential tourism target group.

\subsubsection{Occupational distribution}

The occupational coverage of the survey respondents is relatively wide. Among them, students accounted for the highest proportion at $75 \%$, government agencies and institutions accounted for $9.86 \%$, enterprises and self-employed individuals 
accounted for $9.15 \%$, and economic business sales accounted for $5.99 \%$. In view of the fact that the target group of experiential tourism is mainly young people, and students are the core force, the distribution of this occupation can better reflect the current consumption of "textile and intangible cultural heritage + " experiential tourism in Beijing.

\section{INVESTIGATION AND ANALYSIS OF THE STATUS QUO AND PROBLEMS OF BEIJING "TEXTILE INTANGIBLE CULTURAL HERITAGE $+"$ EXPERIENCING TOURISM}

\subsection{Cognition of textile intangible cultural heritage}

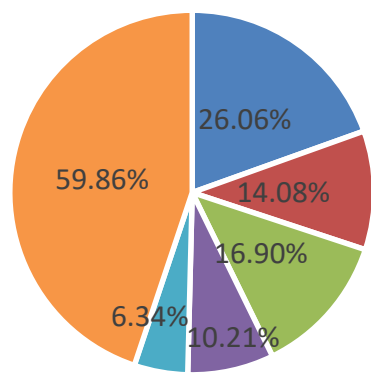

\footnotetext{
- Embroidery: Lu embroidery, Su embroidery, Xia Bu embroidery

- Weaving: Yuyao Tufu Production Technique, Nantong Blue Printed Fabric Tujia Brocade

- Dyeing: Miao batik technique, Li traditional spinning, dyeing and embroidery technique - Costume: Nanjing Cloud Brocade

- Other

No knowledge
}

Figure 1 The situation of textile intangible cultural heritage cognition

It can be seen from Figure 1 that among the interviewees, the proportion of respondents who did not understand textile intangible cultural heritage was $59.86 \%$, close to $60 \%$, and the proportion of respondents who understood textile intangible cultural heritage was roughly $40 \%$. Among them, among the specific categories of textile and intangible cultural heritage, the respondents' knowledge of embroidery accounted for the highest proportion at $26.06 \%$, and textile and intangible cultural heritage clothing at least $10.21 \%$. Weaving and printing and dyeing accounted for roughly the same proportions, respectively. $14.08 \%$ and $16.9 \%$. In general, the general public does not have a high level of awareness of textile intangible heritage

\subsection{Information acquisition channels of textile intangible cultural heritage}

Modern self-media and the Internet are developed, and people have various channels for obtaining textile intangible cultural heritage information, mainly through five major aspects: education (online/offline courses, professional training courses), media (textile intangible cultural heritage publicity, news broadcast, Weaving intangible cultural heritage public account, political relations activities), activities (organizing textile intangible cultural heritage project activities, textile intangible cultural heritage fashion show), recommendations from relatives and friends, and other aspects.

The survey results show that the survey respondents' channels for textile intangible cultural heritage information are mainly through the media (textile intangible cultural heritage propaganda, news broadcasts, textile intangible cultural heritage official accounts, political relations activities), accounting for $56.41 \%$, close to $60 \%$. The second place is education (online/offline courses, professional training courses), accounting for $26.28 \%$. The third place is activities (organization of textile intangible cultural heritage project activities, textile intangible cultural heritage fashion show), accounting for $23.72 \%$, and the last is recommended by relatives and friends. The rapid development of the media has become the main way for the public to obtain textile and intangible cultural heritage information. The media mainly includes four aspects: mobile phones, self-media videos, advertisements, and film and television. Therefore, when giving specific policy recommendations, we can increase publicity investment in the media, and promote the public to understand and pay attention to textile intangible cultural heritage through the media's communication effect.

\subsection{Satisfaction of experience tourism project}

In this paper, the satisfaction evaluation of experience tourism activities in this paper mainly examines people's satisfaction with Beijing experience tourism activities from five aspects: the interest of Beijing experience tourism activities, the diversity of participation, the deep level of culture, the reasonableness of prices, and the experience environment. Beijing's tourism industry is developed. As the capital, it attracts tourists from home and abroad. Experience tourism is one of the manifestations of the tourism industry. The degree of satisfaction of the people with Beijing experience tourism activities also reflects the problems of Beijing experience tourism activities. 




Figure 2 People's Satisfaction with Beijing Experiencing Tourism Activities

It can be seen from Figure 2 that what people are most satisfied with the experience tourism activities in Beijing is the deep level of culture, accounting for $50 \%$, indicating that Beijing experience tourism activities have a profound cultural heritage. The second place is the interestingness of the content, accounting for $33.33 \%$, close to $1 / 3$. The diversity of participation is comparable to the experience environment, accounting for less than $30 \%$. This shows that Beijing experience tourism needs to be improved in the diversity of activities and the environment of experience places. At the same time, it can be seen from the histogram that people are most dissatisfied with the reasonableness of the price of Beijing experience tourism activities, accounting for $16.03 \%$. In the future construction of Beijing experience tourism projects, reasonable pricing should be considered, so that people feel value for money in experience tourism.

\section{4. "Textile Intangible Heritage+" Experience Tourism Development Limitations}

This article divides the existing problems of Beijing's "Textile Intangible Heritage +" experience tourism into three major areas. They are the inadequate publicity of "textile intangible cultural heritage +" experience tourism information, the single form of integration of "textile intangible cultural heritage +" experience tourism, and the lack of effective policy support from relevant local governments. Exploring the key issues in the current development of Beijing's "Textile Intangible Heritage +" experiential tourism by investigating the proportion of people's votes on the current issues, and giving corresponding policy recommendations for the issues that arise.

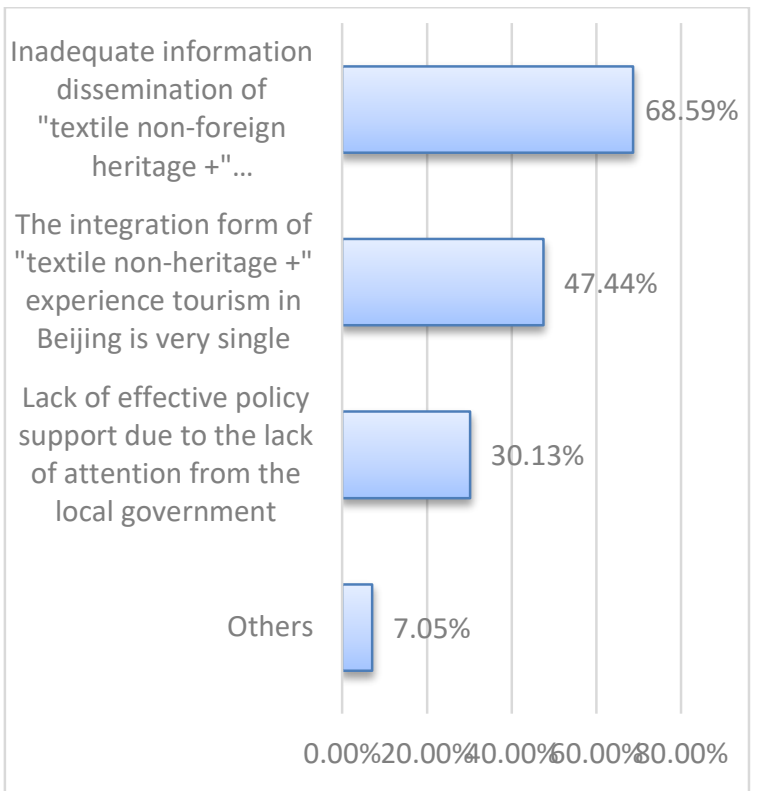

Figure 3 Beijing "Textile Intangible Cultural Heritage+" Experience Tourism Satisfaction

It can be seen from Figure 3 that the inadequate information promotion of "Textile Intangible Heritage $+"$ experience tourism has become the most important problem, accounting for $68.59 \%$, close to $70 \%$. This shows that there is a lack of information and publicity about Beijing's "Textile Intangible Heritage +" experience tourism, and the channels and content of publicity are not in place. The second problem that arises is that the integration of Beijing's "Textile Intangible Heritage + " experience tourism is single, accounting for about $50 \%$. Finally, the local government does not pay attention to it and lacks effective policy support, accounting for $30.13 \%$.

According to the investigation and analysis, the main problem of Beijing's "Textile Intangible Heritage $+"$ experience tourism is its own problems, lack of relevant content and lack of publicity channels, and the integration of experience tourism and textile intangible cultural heritage is single and lacks diversity. 


\section{5. "Textile Intangible Cultural Heritage+" Experiential Tourism Promotion Method}

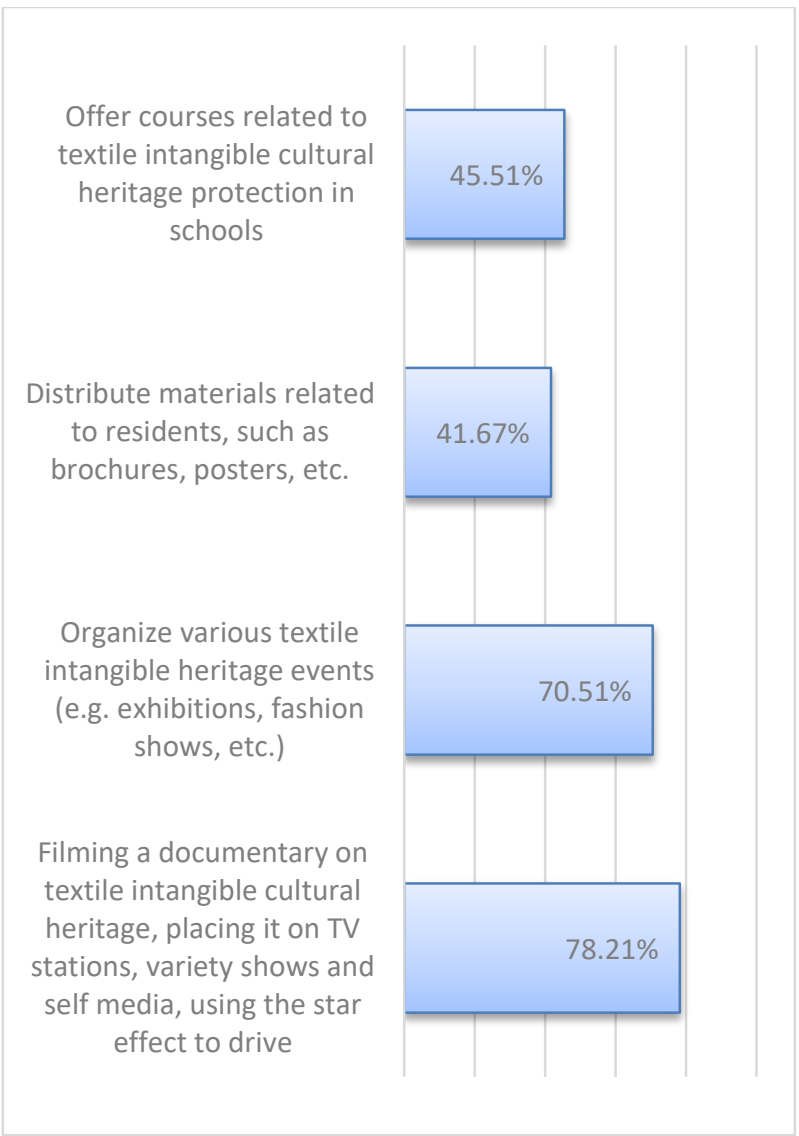

Figure 4 Analysis of "Textile Intangible Cultural Heritage+" Experiential Tourism Promotion Channels

It can be seen from Figure 4 that $78.21 \%$ of the people agree that the textile intangible cultural heritage should be promoted through the filming of textile intangible cultural heritage documentaries, broadcast on television, and the star effect of variety shows from the media. $70.51 \%$ of people hope to organize various textile intangible cultural heritage activities (such as exhibitions, fashion shows) to promote Beijing's "textile intangible cultural heritage $+"$ experience tourism activities. These are the two most popular channels. The approval rate for the distribution of relevant materials to residents and the establishment of related textile and intangible cultural heritage protection courses in schools is roughly the same, which is close to $45 \%$. This shows that media channels and the channels for holding events are the two most supported publicity methods, and they are also the most efficient and convenient publicity channels for the dissemination of "Textile Intangible Cultural Heritage + " experience tourism information. Therefore, we can consider focusing on the media and activities in the promotion, and give a specific promotion plan.

\section{6. "Textile Intangible Cultural Heritage +" Experience Tourism Project Integration Form}

By analyzing the public's approval ratio for various forms of integration, considering the planning of experience tourism projects, catering to the needs of the public, providing high-quality "textile intangible cultural heritage + " experience tourism cultural supply, and building a high-quality cultural industry system in Beijing.

The survey results show that $70 \%$ of the people believe that fashion shows can promote the development of "textile intangible heritage + " experiential tourism, and it is the most popular form of integration. The second place is to hold official events, accounting for $68.59 \%$. In terms of personal experience and exhibitions, the proportion of public support is roughly the same, close to $60 \%$. The public has no obvious preference for the integration of "textile intangible cultural heritage +" experience tourism, but they have a higher degree of support for activities and fashion shows. Therefore, in the future Beijing "Textile Intangible Heritage +" experience tourism integration form, specific policy recommendations should be given to the four major aspects of activities, fashion shows, personal experience, and exhibitions, not just limited to individual integration forms.

\section{CONCLUSION AND EXPERIENCE TOURISM UPGRADE COUNTERMEASURES}

\subsection{Textile Intangible Cultural Heritage + "Experience Tourism Information Acquisition Multi-path}

\subsubsection{Traditional media}

Traditional media include newspapers, radio, and television. You can publish and report on Beijing's "Textile Intangible Cultural Heritage +" experience tourism activities in newspapers and broadcast channels to attract people's attention. In terms of television media, the categories of textile intangible cultural heritage were filmed in the form of special topics, including embroidery, weaving, printing and dyeing, and apparel. The recorded content can be filmed about the culture of specific textile intangible cultural heritage, the production process of the product, and the story of the inheritor. Vivid content can attract the interest of culture lovers and the general public.

\subsubsection{New media}

New media includes the Internet and the mobile terminal of the Internet. In terms of Internet communication: celebrity effect + textile intangible 
cultural heritage propaganda, using the traffic carried by celebrities for propaganda. The promotion of variety shows is the most direct effect. Costumes for performance programs and singing programs allow stars to wear clothing with textile and intangible cultural heritage elements for publicity. Knowledge contest programs can have issues related to textile and intangible cultural heritage. In addition, there are celebrities in the presence of guests to increase the number of viewers watching the show. On the mobile terminal of the Internet-that is, the mobile phone-share public accounts on textile intangible cultural heritage and articles on textile intangible cultural heritage. The content of the propaganda includes related activities of textile intangible cultural heritage, the introduction of a specific textile intangible cultural heritage, stories of textile non-genetic inheritors, and so on. In the process of forwarding the article, raise people's attention to the "Textile Intangible Heritage +" experience tourism activities. In addition, online direct sales can be carried out through the emerging self-media live broadcast method to promote the sales of textile intangible cultural heritage products at home and abroad, and increase people's attention to textile intangible cultural heritage.

\subsection{Countermeasures and suggestions}

\subsubsection{Enhance the characteristics of "textile intangible cultural heritage + " experience tourism activities}

Most of the textile intangible cultural heritage is concentrated in ethnic minority areas, and it takes a long time to participate in experience tourism projects in non-Beijing areas, expensive journeys, and poor urban experience environment. Beijing can introduce the nonBeijing area "Textile Intangible Heritage + " experience tourism project into Beijing, and build Beijing into a national "Textile Intangible Heritage +" experience tourism project base. The experience project that brings together all the textile intangible elements, attracts domestic and foreign tourists to Beijing to experience the visit, which is more efficient and the diversity of experience activities. No need to visit all over the country, just need to experience all textile intangible cultural heritage projects in Beijing, with the characteristics of industrial clusters and multiexperience.

\subsubsection{Improve the overall quality of textile non- genetic inheritors}

The quality of textile non-genetic inheritors varies. Beijing, as a gathering place for the national "Textile Intangible Heritage + " experience tourism activities, attracts textile non-genetic inheritors from all over the country to come to Beijing for employment. Many textile non-genetic inheritors in non-Beijing areas have a low cultural level and cannot adapt to the fast-paced urban life after coming to Beijing. Therefore, the mental health of textile non-genetic inheritors must be regularly rectified and the specific work of the industry must be regulated. This systematic training and management of textile non-genetic inheritors is important for improving the overall quality of textile non-genetic inheritors in Beijing. Quality has a driving effect.

\section{3. "Textile Intangible Cultural Heritage+" Experience Tourism Integration in Diversified Forms}

\subsubsection{Event hosting}

Official activities on textile intangible cultural heritage can be held, such as the China Textile Intangible Cultural Heritage Conference. At present, the China Textile Intangible Cultural Heritage Conference has been held for four sessions. The main content of its activities is to set the theme of the conference, invite people in the industry to give keynote speeches, and display textile intangible cultural heritage works. However, this kind of official event is more well known in the textile industry. It is recommended that the official event textile and intangible cultural heritage conference can be jointly organized with college clothing design performances, so that college students have a real opportunity to participate in the inheritance of textile intangible cultural heritage. The specific method of participation can be through competitions conducted by colleges and universities in the country that set up clothing design majors, and finally select several teams to perform $\mathrm{T}$-stage performances at the official textile and intangible cultural heritage conference or display their works in the form of speeches.

The significance is that textile intangible cultural heritage needs to receive more attention from young people, and it is necessary to start with professionals who will participate in textile intangible cultural heritage work in the future to cultivate their love and confidence in textile intangible cultural heritage. In this way, the official textile and intangible cultural heritage conference is no longer an official symbolic event, but a platform for the ability to show the honors of teachers and students in the industry and universities across the country. This not only has the effect of spreading textile intangible cultural heritage, but also promotes the innovative development of textile intangible cultural heritage products. As Beijing is a gathering place for textile and intangible cultural heritage, the official activities of the Textile and Intangible Cultural Heritage Conference can also establish Beijing's role as a benchmark city for textile and intangible cultural heritage in the country. 


\subsubsection{Fashion show}

In terms of fashion shows, Beijing, as the capital, can gather textile and apparel design talents from all over the country to hold textile and intangible cultural heritage-related apparel auctions and Beijing apparel design competitions. Beijing can create a series of textile and intangible cultural heritage fashion shows and Beijing textile and intangible cultural heritage fashion week. On the one hand, attracting domestic and foreign buyers who love textiles and intangible cultural heritage, clothing buyers, fashion industry managers, and brand owners to create industrial clusters, it can also drive the overall consumption power of Beijing's cultural industry. On the other hand, you can invite well-known models in China to catwalk, and broadcast live on major media to improve their visibility in the industry, internationally, and the model circle.

\subsubsection{Hands-on experience}

In terms of personal experience, Beijing "Textile Intangible Heritage +" experience tourism can set up textile and intangible cultural heritage experience venues, textile and intangible cultural heritage DIY studios, and scenic clothing COSPLAY experience services in terms of integration.

Experience the venue. The textile intangible cultural heritage experience venue provides VR virtual experience, textile intangible cultural heritage clothing and weaving tools experience. Visitors can experience the process of weaving, embroidery, batik, or a combination of the two, and have professional guides wearing textile and intangible cultural heritage in each venue to give tour explanations to improve the overall tourism experience. At the same time, the experience place can purchase textile intangible cultural heritage products, such as cups, pillows, clothing, shoes, bags, etc. with textile intangible cultural heritage elements.

Textile intangible cultural heritage DIY studio. The DIY studio is biased towards the production of textile intangible cultural heritage products, such as experiencing textile intangible cultural heritage embroidery patterns, making backpacks, and DIY handmade ceramics with textile intangible cultural heritage elements. In the DIY workshop, you can set up special areas for family experience, personal experience, couple experience, and friend experience. Creating special areas can avoid unnecessary interference. At the same time, the staff of the DIY studio can also better assist in the explanation.

Scenic textile intangible cultural heritage clothing COSPLAY. Integrating the resources of both parties through the channels of setting up the textile and intangible cultural heritage clothing experience reservation window through the official website of the scenic spot can reduce the cost of the experience, and the reduction of the price is conducive to the increase of the audience. The use of digital networks to achieve the industrialization of textile and intangible cultural heritage clothing at scenic spots, saving passengers' selection time and staff preparation time. At the same time, tourists from all over the world can have a publicity way to become familiar with textile intangible cultural heritage when buying tickets through the official website of Beijing attractions.

\section{ACKNOWLEDGMENTS}

Beijing
(20JCC053)

\section{REFERENCES}

[1] Zhou Yiling. Construction of a digital protection platform for textile intangible cultural heritage [J]. China Textile, 2020(Z5): 114-115.

[2] Luo Xiaoqing, Tan Qingbao. Effective path of nongenetic inheritance of textiles in colleges and universities [J]. Textile Industry and Technology, 2020, 49(10): 191-192+19

[3] Jie Jie. Research on the development of tourism and catering based on IPA analysis from the perspective of experience economy-Taking Gansu Province as an example [J]. China Economic and Trade Guide (Secondary), 2021(05): 64-67.

[4] Liang Long. The development of textile nongenetic inheritance has entered a new era-The 3rd China Textile Intangible Cultural Heritage Conference was held in Kunming [J]. China Textile, 2019(12): 146-147.

[5] Shi Yun. Introspection on the status quo of noninherited inheritance of Leizhou Gebu weaving technology from the perspective of art management [J]. Light Textile Industry and Technology, 2021, 50(01): 72-76.

[6] Li Chunxiao, Wang Yanzhen, Qu Hongjian. Research on the Spatio-temporal Characteristics of Textile Intangible Cultural Heritage Attention and Its Communication Strategy-An Empirical Analysis Based on Baidu Index [J]. Silk, 2021, 58(01): 52-58.

[7] Wang Limin. Research on the integration of characteristic tourism projects and new media [J]. Tourism and Photography, 2021(06): 22-23. 